in vivo $35: 549-554(2021)$

doi:10.21873/invivo.12290

\title{
Preoperative Octenidine Application in Breast Reconstruction Surgery
}

\author{
JENS HACHENBERG $^{1 *}$, ELLEN ACIS ${ }^{2}$, MAXIMILIAN MATTES AUER-SCHMIDT ${ }^{3}$, MATHIAS WARM ${ }^{2,4}$, \\ WOLFRAM MALTER ${ }^{2,3}$, FABINSHY THANGARAJAH ${ }^{2}$ and CHRISTIAN EICHLER ${ }^{2,4,5^{*}}$ \\ ${ }^{1}$ Department of Gynecology and Obstetrics, Hannover Medical School, Hannover, Germany; \\ ${ }^{2}$ Department of Gynecology and Obstetrics, University of Cologne, Cologne, Germany; \\ ${ }^{3}$ Faculty of Medicine and University Hospital Cologne, The University of Cologne, Cologne, Germany; \\ ${ }^{4}$ Department of Gynecology and Obstetrics, Frauenklinik Holweide, Kliniken der Stadt Köln, Cologne, Germany; \\ ${ }^{5}$ German Center for Material Science in Gynecology and Senology (DZMGS), Cologne, Germany
}

\begin{abstract}
Background/Aim: Postoperative infection in implant-based reconstructive breast surgery is a common problem. The preoperative application of a disinfecting washing agent may reduce postoperative infection rates. This retrospective analysis aimed to evaluate whether preoperative Octenisan ${ }^{\circledR}$ application yields a reduction in postoperative complications or infection rates in breast reconstructive surgery. Patients and Methods: Between 2016 and 2019, 127 women received implant-based breast reconstruction at the municipal hospital of Cologne, Holweide, Germany. A total of 197 treatments were performed. After giving consent, patients were asked to use Octenisan ${ }^{\circledR}$ wash lotion for five days before breast reconstructive surgery. All patients were asked by a simple questionnaire whether they performed showering and washing according to the proposed protocol. In 96 cases patients did adhere to the protocol. In 101 cases they did not. Patient cohorts were then divided into patients who had applied Octenisan ${ }^{\circledR}$ wash lotion and patients who had not. Endpoints were defined as minor complications with no implant loss and major complications with consecutive implant loss. Results: Patient adherence to the application regimen was $48.7 \%$. Overall minor complications occurred in $34.4 \%$ with preoperative Octenidine usage and $36.6 \%$
\end{abstract}

This article is freely accessible online.

*These Authors contributed equally to this study.

Correspondence to: Dr. med. Jens Hachenberg, Klinik für Frauenheilkunde und Geburtshilfe, Medizinische Hochschule Hannover, Carl-Neuberg-Str. 1, 30625 Hannover, Germany. Tel: +49 15735516322, e-mail: Hachenberg.Jens@mh-hannover.de

Key Words: Octinidine, breast reconstruction surgery, topical antiseptics, Preoperative body washing. without preoperative Octenidine usage. Major complications happened in $7 \%$ with preoperative Octenidine and 5\% without Octenidine. Overall, there was no significant difference concerning minor or major complication rates. Conclusion: Preoperative washing protocols involving the Octenisan ${ }^{\circledR}$ wash lotion is relatively cheap and easy to follow. There is evidence that washing protocols result in a reduction of $S$. aureus infections leading to a better perioperative outcome. Octenisan ${ }^{\circledR}$ is safe to use in implantbased breast reconstructive surgery and is not associated with higher risks for patients. Our study did not yield any significant reduction in perioperative and postoperative complication and infection rates. This is attributed to a relatively low study population. Wash lotion compliance was only 48.7\%. Proper patient education is crucial. With those preliminary data, it is now possible to design a larger analysis since patient adherence to washing protocol with Octenisan ${ }^{\circledR}$ wash lotion has been established.

Postoperative wound infections, pneumonia, and urinary tract infections account for the most common nosocomial infections in hospitals. Wound infections represent the largest part $(24.3 \%)$ of nosocomial infections followed by urinary tract infections $(23.2 \%)$ and pneumonia $(21.7 \%)$. Whereas for breast surgery perioperative and postoperative mortality is very low postoperative wound infection is the most frequent morbid complication occurring in 4.3-8.3\% $(1,2)$. The reason for the loss of a breast implant in breast reconstructive surgery is in approximately $83 \%$ of cases a perioperative or postoperative infection. About half of all implant losses occur within 90 days after surgery. S. aureus and S. epidermidis are some of the most common of all detected germs in nosocomial infections and mainly responsible for implant losses (3-5). Decreasing perioperative and postoperative infections, therefore, is of utter importance. 
Bode et al. performed a randomized, double-blinded, placebo-controlled multicenter trial between 2005 and 2007. By screening 6,771 presurgical patients they identified a total of 1,251 patients who were nasal carriers of $S$. aureus. A total of 917 of those patients were enrolled in an intentionto-treat study. They were able to significantly decrease the number of postoperative wound infections by treating nasal $S$. aureus carriers with mupirocin ointment in combination with chlorhexidine gluconate soap (6). Ammerlaan et al. conducted a trial to eradicate $S$. aureus carriers. They were able to eradicate $60 \%$ of $S$. aureus carriers after one trial and could increase that number to $80 \%$ success rate after 5 trials (7). Notably, the resistance to the topic of antibiotic mupirocin is increasing worldwide (8). Preoperative bathing with antiseptic agents has been proven to be effective in reducing skin microflora and eradicating $S$. aureus (9). The World health organization (WHO) and the Centre for disease control and prevention (CDC) guidelines consider preoperative bathing with soap (antimicrobial or plain) at least the night before the operative day as "good clinical practice" $(10,11)$.

Octenidine (Octenisan ${ }^{\circledR}$ Wash lotion, Schülke\& Mayr $\mathrm{GmbH}$, Norderstedt, Germany) is a modern antiseptic with a broad antimicrobial spectrum against Grampositive and Gramnegative bacteria including MRSA plaque-forming bacteria, Chlamydia, Mycoplasma, and fungi (12). Octenidine is not percutaneously absorbed and partly remains on the location of the application. It, therefore, exerts a sustained antimicrobial effect. Octenidine is very effective in the eradication of MRSA-carriers (13). In contrast to antibiotic treatment, bacteria do not undergo a selection of resistance against Octenidine due to its unspecific antimicrobial mechanism (14). Octenidine, therefore, seems to be a promising therapeutic approach in reducing the number of perioperative and postoperative infections.

This retrospective analysis evaluates the following objectives:

- Is Octenisan ${ }^{\circledR}$ safe to use in breast reconstructive surgery?

- Does Octenisan ${ }^{\circledR}$ application yield a reduction in perioperative and postoperative complications and infection rates in breast reconstructive surgery?

- Is the usage of Octenisan ${ }^{\circledR}$ wash lotion applicable for all patients?

- Is the usage of Octenisan ${ }^{\circledR}$ wash lotion cost-effective?

\section{Patients and Methods}

Between 2016 and 2019, 127 women received implant-based breast reconstruction at the municipal hospital of Cologne, Holweide, Germany. A total of 197 treatments were performed. The protocol was constructed analogously to the protocol of Bode et al. and Stambough et al. as a universal approach $(6,15)$. The intention was to treat all patients. There was no admission screening for MSSA/
MRSA. After giving consent patients were asked to use Octenisan ${ }^{\circledR}$ Wash lotion for five days before breast reconstructive surgery and thoroughly wash and clean especially at and around the incision site. In 96 cases patients performed showering according to protocol. In 101 cases the protocol was not followed due to incompliance. For analysis, patient cohorts were divided into patients who applied Octenisan ${ }^{\circledR}$ wash lotion and patients who did not. An overview of all patient characteristics is found in Table I. Endpoints were defined as minor complications with no implant loss and major complications with consecutive implant loss. All complications and complication rates for both study groups are illustrated in Table II. Infection was defined according to the U.S. Centers for Disease Control and Prevention (CDC)/ National Healthcare Safety Network definition. Infections occurring after breast implant surgery were characterized by three or more of the following findings: local swelling, Pain, seroma, erythema, fever, pus, wound dehiscence, or perforation of the skin. All Events occurred within 90 days after surgery.

Statistics. Statistical analysis was performed using the VassarStats1 (Vassar College, Poughkeepsie, NY, USA) statistics program. ANOVA analysis and $t$-tests were used to evaluate significances when appropriate.

\section{Results}

Patient adherence to the application regimen was $48.7 \%$. In 96 cases patients used Octenisan ${ }^{\circledR}$ wash lotion preoperatively whereas in 101 cases patients did not. Both two groups did not differ significantly in age and BMI (Table I). There was a significantly lower part of nicotine abuse in the group of Octenisan ${ }^{\circledR}$ wash lotion users $(\mathrm{p}=0.017)$. The indications for implant insertion were prophylactic $(27.7 \%$ vs. $25 \%)$, oncological $(61.4 \%$ vs. $55.2 \%)$ or cosmetic reasons $(10.9 \%$ vs. $19.9 \%$ ). The side of surgery was $46.9 \%$ left and $53.1 \%$ right for Octenisan ${ }^{\circledR}$ wash lotion users. Non-Octenisan ${ }^{\circledR}$ wash lotion users' side of surgery was $57.4 \%$ left and $42.6 \%$ right. Minor complications comprised seroma in $13.5 \% \mathrm{vs}$. $10.9 \%$, capsular fibrosis in $4.2 \% \mathrm{vs} .6 .9 \%$, Infection (without no operative revision) in $10.4 \%$ vs. $7.9 \%$, Immediate implant rotation or dislocation in $1 \%$ vs. $1 \%$, Red-Breast-Syndrome in $0 \% v s .2 \%$, Impaired wound healing or necrosis (without operative revision) in $4.2 \% \mathrm{vs} .4 \%$ and Haematoma (with operative revision without implant loss) in $1 \%$ vs. $4 \%$. Overall minor complications occurred in $34.4 \%$ with preoperative Octenidine usage and $36.6 \%$ without preoperative Octenidine usage. Major complication comprised infection of the expander or breast implant with implant loss in $3.1 \% \mathrm{vs.} 2 \%$, Implant loss because of allergic reaction in $0 \%$ vs. $1 \%$, Wound healing or necrosis in $1 \% v s$. $2 \%$, and massive rebleeding or implant malfunction with implant loss in $1 \%$ vs. $2 \%$. Capsular fibrosis which leads to implant change or DIEP was classified as late complications and occurred in $3.1 \%$ vs. $3 \%$. Overall, there was no significant difference concerning minor or major complication rates (Table II). 
Hachenberg et al: Octenidine in Breast Surgery

Table I. Characteristics of patients who used Octinisan (Preoperative Octinisan) preoperatively and those who did not (Non-preoperative Octinisan).

\begin{tabular}{|c|c|c|c|c|c|}
\hline & \multicolumn{2}{|c|}{ Preoperative octinisan } & \multicolumn{2}{|c|}{ Non-preoperative octinisan } & \multirow[b]{2}{*}{$p$-Value } \\
\hline & Number of cases & $\%$ & Number of cases & $\%$ & \\
\hline & 101 & 100 & 96 & 100 & \\
\hline Number of patients & 65 & & 62 & & \\
\hline Gender (female) & 101 & 100 & 96 & 100 & \\
\hline Median age (Range) & $49(18-82)$ & & $51(16-73)$ & & 0.727 \\
\hline Median BMI (Range) & $22.7(16.9-37.7)$ & & $23.2(17.8-40.5)$ & & 0.976 \\
\hline Nicotine abuse & 39 & 38.6 & 22 & 22.9 & 0.017 \\
\hline \multicolumn{6}{|l|}{ Side/Breast } \\
\hline Left & 58 & 57.4 & 45 & 46.9 & \\
\hline Right & 43 & 42.6 & 51 & 53.1 & \\
\hline \multicolumn{6}{|l|}{ Implant insertion } \\
\hline Prophylactic & 28 & 27.7 & 24 & 25 & 0.663 \\
\hline Oncological & 62 & 61.4 & 53 & 55.2 & 0.380 \\
\hline Cosmetic & 11 & 10.9 & 19 & 19.8 & 0.082 \\
\hline
\end{tabular}

BMI: Body mass index.

Table II. Minor and major complications of patients who used Octinisan (Preoperative Octinisan) preoperatively and those who did not (Nonpreoperative Octinisan).

\begin{tabular}{|c|c|c|c|c|c|}
\hline & \multicolumn{2}{|c|}{ Non-preoperative octinisan } & \multicolumn{2}{|c|}{ Preoperative octinisan } & \multirow[b]{2}{*}{$p$-Value } \\
\hline & Number of cases & $\%$ & Number of cases & $\%$ & \\
\hline & 101 & 100 & 96 & 100 & \\
\hline Number of patients & & 65 & & 62 & \\
\hline \multicolumn{6}{|l|}{ Minor complications (no implant loss) } \\
\hline Overall & 37 & 36.6 & 33 & 34.4 & 0.740 \\
\hline Seroma & 11 & 10.9 & 13 & 13.5 & 0.572 \\
\hline Capsular Fibrosis & 7 & 6.9 & 4 & 4.2 & 0.399 \\
\hline Infection (no operative revision) & 8 & 7.9 & 10 & 10.4 & 0.543 \\
\hline Immediate Implant rotation/ dislocation & 1 & 1 & 1 & 1 & Not applicable \\
\hline Red-Breast-Syndrome & 2 & 2 & 0 & 0 & 0.166 \\
\hline Impaired wound healing or necrosis (no operative revision) & 4 & 4 & 4 & 4.2 & Not applicable \\
\hline Haematoma (operative revision, no implant loss) & 4 & 4 & 1 & 1 & 0.192 \\
\hline \multicolumn{6}{|l|}{ Major complications (with implant loss) } \\
\hline Overall & 7 & 7 & 5 & 5 & 0.610 \\
\hline Infection of expander/ breast implant with implant loss & 2 & 2 & 3 & 3.1 & 0.584 \\
\hline Implant loss because of allergic reaction & 1 & 1 & 0 & 0 & 0.327 \\
\hline Wound healing or necrosis with implant loss & 2 & 2 & 1 & 1 & 0.590 \\
\hline Massive rebleeding or implant malfunction with implant loss & 2 & 2 & 1 & 1 & 0.590 \\
\hline \multicolumn{6}{|l|}{ Late complications } \\
\hline Capsular fibrosis which led to implant change or DIEP & 3 & 3 & 3 & 3.1 & Not applicable \\
\hline
\end{tabular}

Seroma: Symptomatic, detectable by ultrasound and requires at least one needle aspiration; DIEP: deep inferior epigastric perforator.

\section{Discussion}

Health-care associated infections (HCAI) mainly comprise postoperative wound infections, pneumonia, and urinary tract infections and affect 1.7 million hospitalized patients in the U.S. alone per year. One in 17 dies due to HCAI (16). In
2016 the German prevalence of nosocomial infection was $4.6 \%$ of all patients. HCAI is a worldwide problem and is not restricted to one country (17). Apart from obvious medical complications caused by nosocomial infection, there is also a financial dimension resulting in an increased financial burden per patient, a prolonged length of stay as 
well as a higher 30-day readmission rate (18). It is, therefore, crucial to reducing the incidence of HCAI.

For patient-driven regimens, our study highlights the importance of proper patient education. All participants were asked to use the Octenisan ${ }^{\circledR}$ wash lotion. The patient's adherence to the application regimen was only $48.7 \%$. This result indicates a great deficiency in current patient-driven regimens. Interestingly adherence rate of drug intake in chronic disease is reportedly around $50 \%$ as well (19). Other studies showed compliance levels to preoperative washing protocols as low as $22 \%$ (20). Modern methods for increasing patient compliance include educational interventions, behavioral interventions, self-management interventions, or risk communication interventions. For preoperative bathing regimens, it could be shown that one hour of preoperative patient education significantly increased patients' adherence rates (21). In finding a potent treatment for the reduction of nosocomial wound infections self-administered regimens require an effective and easy-to-follow patient education to ensure proper medication adherence rates.

Up to date, chlorhexidine ( $2 \%$ or $4 \%$ ) is the most commonly used applicant worldwide. It significantly reduces epidermal bioburden. Chlorhexidine is superior to regular soap as it binds to skin proteins and therefore continues to exert its antiseptic effects (22). Current studies show that Octenidine is equally efficient as Chlorhexidine (23). The ABATE Infection Cluster Randomized Trial showed that decolonization with universal Chlorhexidine bathing and targeted mupirocin for MRSA carriers did not reduce multidrug-resistant organisms or all-pathogen bloodstream infection in all non-critical care patients (24). Nonetheless, Kapadia et al. were able to demonstrate that the preoperative usage of Chlorhexidine reduced the incidence of surgical wound infections in total hip arthroplasty (25). A carefully selected population, therefore, seems to benefit from preoperative antimicrobial soap bathing.

In our trial, we were not able to show a significant benefit of preoperative body washing with Octenisan ${ }^{\circledR}$ wash lotion. Considering all minor and major complication rates Octenisan ${ }^{\circledR}$ wash lotion did not prove to be inferior. We observed a numerical tendency leaning towards the usage of Octenidine for minor ( $8 v s .10)$ and major complications (2 $v s .3)$. The overall infection rate was $11.7 \%$ whereas loss of implant due to infection was $2.5 \%$. Comparing infection rates to other studies there was no significant difference. Franchelli et al. observed infection rates in 240 breast reconstruction operations in patients with breast cancer. Though the overall infection rate $(6.7 \%)$ was slightly lower compared to our population the rate of implant loss due to infection was considerably higher (4.6\%) (26).

Larger numbers are certainly needed and are currently being adhered to as Octenisan ${ }^{\circledR}$ is continuously given to patients. At a real-life application of only $50 \%$ of patients, we would require approximately $n=4,000$ real-life patients to estimate the above-mentioned $n=1,941$ (with a $100 \%$ application rate). A multicenter analysis will be available in approximately 5 years.

An advantage of this study is its unique study population. To our best knowledge thus far there is no study investigating the possible advantages and disadvantages of the preoperative application of Octenisan ${ }^{\circledR}$ wash lotion. This is a single-center study with relatively low numbers. Additionally, a possible bias in this study could be the significantly higher number of smokers in patients who performed the body washing with Octenisan ${ }^{\circledR}$ wash lotion. Smoking is known to be a major risk factor concerning wound infections and prolonged wound healing $(27,28)$. The showering technique of patients was not recorded and is likely to be another bias. This study there is considered preliminary.

Importantly, we were able to show that Octenisan ${ }^{\circledR}$ wash lotion is not associated with any certain risks and seems safe to use for patients.

Octenisan ${ }^{\circledR}$ wash lotion is an easy-to-handle medium with no known major side-effects. It is relatively inexpensive. The costs for one treatment are $3 €\left(500 \mathrm{ml}\right.$ Octenisan ${ }^{\circledR}$ Wash lotion). This does not include the relative costs for prescription, dispensing, information material, or time for counseling. An English study showed that general ward costs per bed day are about $£ 586.59$ (around $638 €$ ). Notably, this did not include additional costs for isolation or ICU which have to be considered in the case of HCAI. Annual costs for HCAI were calculated to amount to up to $£ 11.9$ million (12.9€) (29). In Germany, Arefian et al. measured the additional costs attributable to nosocomial infections to $€ 5.823-€ 11.840$ (\$7.453-\$15.155) per infected patient (30). Though we were not able to demonstrate a significant benefit by preoperative bathing for Octenisan ${ }^{\circledR}$ wash lotion this study shows that Octenisan ${ }^{\circledR}$ wash lotion can be considered to be generally safe to use for breast reconstruction surgery. As other studies were able to show a clear benefit of preoperative bathing especially in the case of usage of alloplastic material it is necessary to evaluate the benefit of Octenisan ${ }^{\circledR}$ wash lotion in a larger population.

\section{Conclusion}

Preoperative washing protocols involving the Octenisan ${ }^{\circledR}$ wash lotion are relatively cheap and easy to follow. There is evidence that washing protocols result in a reduction of $S$. aureus infections leading to a better perioperative outcome. Octenisan ${ }^{\circledR}$ is safe to use in implant-based breast reconstructive surgery and is not associated with higher risks for patients. Our study did not yet yield a significant reduction in perioperative and postoperative complication and infection rates. This is attributed to low numbers. Wash lotion compliance was only $48.7 \%$. Proper patient education is crucial. With those preliminary data, it is now possible to 
design a larger analysis since patient adherence to washing protocol with Octenisan ${ }^{\circledR}$ wash lotion has been established.

\section{Conflicts of Interest}

All Authors declare that there are no conflicts of interest regarding this study.

\section{Authors' Contributions}

CE and JH designed the study. All Authors contributed to data collection and analysis. JH and CE wrote the article. All Authors revised and approved the final form. CE was the supervisor.

\section{References}

1 El-Tamer MB, Ward BM, Schifftner T, Neumayer L, Khuri S and Henderson W: Morbidity and mortality following breast cancer surgery in women: national benchmarks for standards of care. Ann Surg 245: 665-671, 2007. PMID: 17457156. DOI: 10.1097/01.sla.0000245833.48399.9a

2 Degnim AC, Throckmorton AD, Boostrom SY, Boughey JC, Holifield A, Baddour LM and Hoskin TL: Surgical site infection after breast surgery: impact of 2010 CDC reporting guidelines. Ann Surg Oncol 19: 4099-4103, 2012. PMID: 22732837. DOI: 10.1245/s10434-012-2448-6

3 Hachenberg $T$, Sentürk M, Jannasch $\mathrm{O}$ and Lippert $\mathrm{H}$ : Postoperative wundinfektionen: Pathophysiologie, risikofaktoren und präventive konzepte. Anaesthesist 59: 851-868, 2010.

4 Szymankiewicz M, Nowikiewicz T and Biedka M: Significance of infections in implant loss after breast reconstruction in the course of breast cancer treatment. Pol J Microbiol 68: 343-351, 2019. PMID: 31880880 . DOI: $10.33073 / \mathrm{pjm}-2019-037$

5 Gastmeier P, Behnke M, Breier A-C, Piening B, Schwab F, Dettenkofer $M$ and Geffers C: [Healthcare-associated infection rates: measuring and comparing. Experiences from the German National Nosocomial Infection Surveillance System (KISS) and from other surveillance systems]. Bundesgesundheitsblatt, Gesundheitsforschung, Gesundheitsschutz 55: 1363-1369, 2012. PMID: 23114434. DOI: 10.1007/s00103-012-1551-y

6 Bode LGM, Kluytmans JAJW, Wertheim HFL, Bogaers D, Vandenbroucke-Grauls CMJE, Roosendaal R, Troelstra A, Box ATA, Voss A, van der Tweel I, van Belkum A, Verbrugh HA and Vos MC: Preventing surgical-site infections in nasal carriers of Staphylococcus aureus. N Engl J Med 362: 9-17, 2010. PMID: 20054045. DOI: 10.1056/NEJMoa0808939

7 Ammerlaan HSM, Kluytmans JAJW, Berkhout H, Buiting A, de Brauwer EIGB, van den Broek PJ, van Gelderen P, Leenders SACAP, Ott A, Richter C, Spanjaard L, Spijkerman IJB, van Tiel FH, Voorn GP, Wulf MWH, van Zeijl J, Troelstra A, Bonten MJM, van de Berg CMF, Bosman J, Bremer A, Bril W, Commeren D, van Essen G, Gigengack-Baars A, van Kasteren MME, Lommerse EJM, Mascini E, Renders NHM, van Rijen M, Schellekens J, Smeets E, Sprangers T, Vandenbroucke-Grauls CMJE, Verbon A, Verduin K, Wagenvoort JHT and van Wijngaarden P: Eradication of carriage with methicillin-resistant Staphylococcus aureus: effectiveness of a national guideline. J Antimicrob Chemother 66: 2409-2417, 2011. PMID: 21719473. DOI: $10.1093 / \mathrm{jac} / \mathrm{dkr} 243$
8 Fawley WN, Parnell P, Hall J and Wilcox MH: Surveillance for mupirocin resistance following introduction of routine perioperative prophylaxis with nasal mupirocin. J Hosp Infect 62: 327332, 2006. PMID: 16377029. DOI: 10.1016/j.jhin.2005.09.022

9 Kaiser AB, Kemodle DS, Barg NL and Petracek MR: Influence of preoperative showers on staphylococcal skin colonization: A comparative trial of antiseptic skin cleansers. Ann Thorac Surg 45: 35-38, 1988. PMID: 3337574. DOI: 10.1016/S0003-4975(10) 62391-0

10 Allegranzi B, Bischoff P, de Jonge S, Kubilay NZ, Zayed B, Gomes SM, Abbas M, Atema JJ, Gans S, van Rijen M, Boermeester MA, Egger M, Kluytmans J, Pittet D and Solomkin JS: New WHO recommendations on preoperative measures for surgical site infection prevention: an evidence-based global perspective. Lancet Infect Dis 16: e276-e287, 2016. PMID: 27816413. DOI: 10.1016/S1473-3099(16)30398-X

11 Keely Boyle K, Rachala S and Nodzo SR: Centers for Disease Control and Prevention 2017 Guidelines for prevention of surgical site infections: Review and relevant recommendations. Curr Rev Musculoskelet Med 11: 357-369, 2018. PMID: 29909445. DOI: $10.1007 / \mathrm{s} 12178-018-9498-8$

12 Malinovskií NN, Reshetnikov EA, Rubashnaia IE, Mal'nikova GN and Mitiukov AP: Antiseptics on the base of Octenidine Hydrochloride. Khirurgiia (Mosk) (8): 8-10, 1997. PMID: 9480391.

13 Hübner N-O, Wander K, Ryll S and Kramer A: [Successful decolonisation of MRSA-positive patients]. Med Monatsschr Pharm 32: 87-94; quiz 95-6, 2009. PMID: 19402334. DOI: $10.3205 / \mathrm{dgkh000129}$

14 Al-Doori Z, Goroncy-Bermes P, Gemmell CG and Morrison D: Low-level exposure of MRSA to octenidine dihydrochloride does not select for resistance. J Antimicrob Chemother 59: 12801281, 2007. PMID: 17439976. DOI: 10.1093/jac/dkm092

15 Stambough JB, Nam D, Warren DK, Keeney JA, Clohisy JC, Barrack RL and Nunley RM: Decreased hospital costs and surgical site infection incidence with a universal decolonization protocol in primary total joint arthroplasty. J Arthroplasty 32: 728-734.e1, 2017. PMID: 27823845. DOI: 10.1016/j.arth.2016.09.041

16 Haque M, Sartelli M, McKimm J and Abu Bakar M Bin: Health care-associated infections; an overview. Infect Drug Resist 11: 2321-2333, 2018. PMID: 30532565. DOI: 10.2147/IDR.S177247

17 Behnke M, Hansen S, Leistner R, Diaz LAP, Gropmann A, Sohr D, Gastmeier P and Piening B: Nosocomial infection and antibiotic use. Dtsch Arztebl Int 110: 627-633, 2013. PMID: 24133543. DOI: 10.3238 /arztebl.2013.0627

18 Shepard J, Ward W, Milstone A, Carlson T, Frederick J, Hadhazy $\mathrm{E}$ and Perl T: Financial impact of surgical site infections on hospitals: the hospital management perspective. JAMA Surg 148: 907-914, 2013. PMID: 23965750. DOI: 10.1001/jamasurg. 2013.2246

19 Lam WY and Fresco P: Medication adherence measures: An overview. Biomed Res Int 2015: 217047, 2015. PMID: 26539470. DOI: $10.1155 / 2015 / 217047$

20 Kapadia BH, Cherian JJ, Issa K, Jagannathan S, Daley JA and Mont MA: Patient compliance with preoperative disinfection protocols for lower extremity total joint arthroplasty. Surg Technol Int 26: 351-354, 2015. PMID: 26055031.

21 Levieddin JI, Chen KK, Kim K and Schwarzkopf R: Does a one hour educational class improve compliance of chlorhexidine gluconate baths prior to operation? Case Stud Surg 3: 5, 2017. DOI: $10.5430 /$ css.v3n3p5 
22 Huang SS: Chlorhexidine-based decolonization to reduce healthcare-associated infections and multidrug-resistant organisms (MDROs): Who, what, where, when, and why? J Hosp Infect 103: 235-243, 2019. PMID: 31494130. DOI: 10.1016/j.jhin.2019.08.025

23 Brill F, Radischat N, Goroncy-Bermes P and Siebert J: Residual antiseptic efficacy of octenidine dihydrochloride versus chlorhexidine gluconate in alcoholic solutions. Antimicrob Resist Infect Control 4: P33, 2015. DOI: 10.1186/2047-2994-4S1-P33.

24 Huang SS, Septimus E, Kleinman K, Moody J, Hickok J, Heim L, Gombosev A, Avery TR, Haffenreffer K, Shimelman L, Hayden MK, Weinstein RA, Spencer-Smith C, Kaganov RE, Murphy MV, Forehand T, Lankiewicz J, Coady MH, Portillo L, Sarup-Patel J, Jernigan JA, Perlin JB and Platt R: Chlorhexidine versus routine bathing to prevent multidrug-resistant organisms and all-cause bloodstream infections in general medical and surgical units (ABATE Infection trial): a cluster-randomised trial. Lancet 393: 1205-1215, 2019. PMID: 30850112. DOI: 10.1016/S0140-6736(18)32593-5

25 Kapadia BH, Johnson AJ, Daley JA, Issa K and Mont MA: Preadmission cutaneous chlorhexidine preparation reduces surgical site infections in total hip arthroplasty. J Arthroplasty 28: 490493, 2013. PMID: 23114192. DOI: 10.1016/j.arth.2012.07.015

26 Franchelli S, Vassallo F, Porzio C, Mannucci M, Priano V, Schenone E, Leone MS, Canavese G, Santi P and De Maria A: Breast implant infections after surgical reconstruction in patients with breast cancer: Assessment of risk factors and pathogens over extended post-operative observation. Surg Infect (Larchmt) 13: 154-158, 2012. PMID: 22568922. DOI: 10.1089/sur.2011.004
27 Sørensen LT, Hørby J, Friis E, Pilsgaard B and Jørgensen T: Smoking as a risk factor for wound healing and infection in breast cancer surgery. Eur J Surg Oncol 28: 815-820, 2002. PMID: 12477471. DOI: 10.1053/ejso.2002.1308

28 Schmid M, Sood A, Campbell L, Kapoor V, Dalela D, Klett DE, Chun FKH, Kibel AS, Sammon JD, Menon M, Fisch M and Trinh Q-D: Impact of smoking on perioperative outcomes after major surgery. Am J Surg 210: 221-229.e6, 2015. PMID: 25980408. DOI: 10.1016/j.amjsurg.2014.12.045

29 Guest JF, Keating T, Gould D and Wigglesworth N: Modelling the costs and consequences of reducing healthcare-associated infections by improving hand hygiene in an average hospital in England. BMJ Open 9: e029971, 2019. PMID: 31575536. DOI: 10.1136/bmjopen-2019-029971

30 Arefian H, Hagel S, Heublein S, Rissner F, Scherag A, Brunkhorst FM, Baldessarini RJ and Hartmann M: Extra length of stay and costs because of health care-associated infections at a German university hospital. Am J Infect Control 44: 160-166, 2016. PMID: 26521700. DOI: 10.1016/j.ajic.2015.09.005

Received October 19, 2020

Revised November 21, 2020

Accepted November 28, 2020 